\title{
Aquaponics in Bangladesh: current status and future prospects
}

\author{
Kamrun Naher Azad ${ }^{\mathrm{a}}$, M. A. Salam ${ }^{\mathrm{a}}$ and Khairun Naher Azad ${ }^{\mathrm{b}}$ \\ aDept. of Aquaculture, Faculty of Fisheries, Bangladesh Agricultural University, Mymensingh-2202 \\ bFisheries and Marine Resource Discipline, Khulna University, Khulna-9208, Bangladesh \\ $\bowtie$ kamrunnaherkeya003@gmail.com (Azad, K. N.), Published: 15 April 2016
}

\begin{abstract}
Bangladesh is a densely populated country in the world having small land and vast water area. The country has excellent fish culture potentiality because of its abundant water resources. Currently aquaculture is being intensified in Bangladesh to meet the demand of fish protein for increasing population. Agricultural land is also being converted to other uses everyday that is creating pressure on natural resources. Lack of food security and food safety are also serious problems here. Aquaponics, as a combined system of recirculating aquaculture and hydroponics, is an innovative technology in Bangladesh which could contribute to addressing these problems. However, there is a lack of quantitative research to support the development of economically feasible aquaponic systems in the country. Although many studies have addressed some scientific aspects, there has been limited focus on commercial implementation. The analysis shows that in aquaponic system water use is minimum, fish and vegetable production per unit area is higher than the conventional aquaculture and agricultural systems. Therefore, aquaponics have ample scope of enhancement of sustainable food production, especially in adverse geographical context of Bangladesh.
\end{abstract}

Key Words: Aquaponics, Recirculating aquaculture, Current status and Future prospects

Cite article: Azad, K. N., Salam, M. A. \& Azad, K. N. (2016). Aquaponics in Bangladesh: current status and future prospects. Journal of Bioscience and Agriculture Research, 07(02), 669-677.

Article distributed under terms of a Creative Common Attribution 4.0 International License.

\section{Introduction}

Fisheries and aquaculture play a crucial role as a source of animal protein for billions of people worldwide and support the livelihoods of 10-12\% inhabitants in the world. In 2011, global aquaculture production was increased to 62.7 from 59 million tons in 2010 of which $89 \%$ came from Asia where Bangladesh achieved $5^{\text {th }}$ position $(F A 0,2012)$ which was replaced by $4^{\text {th }}$ position through advancement in 2013 (FAO, 2014). Demand for fish is leaping with the population increase in Bangladesh for the last three decades (FAO, 2012) which has increased the land use competition between agricultural crop production and fish farming (Ahmed and Garnett, 2011).

Moreover, land gets shrinking, reckless population growth, manmade environmental pollution and impact of climate change creates new challenges to the country's agriculture sector that has emphasized on integrate crop and fish farming like aquaponics (Salam et al., 2014). The word "Aquaponics" is the marriage of 'Aquaculture' and 'Hydroponics' and at the same time it shares some common attributes of both the systems, which is something far more developed and eventually, unique 
from either of them. Aquaponics is a typical urban agriculture, a combination of two different cultures: aquaculture or farming fish and hydroponics or crop production in soilless substrate. It is the symbiotic relation between the fish and vegetables where fish provides fertilizer to the plants, in return plants help to purify the wastewater as they use the nutrients where the fish live in (Roe and Midmore, 2008). The aquaponics has control on farming systems which can protect the crops from diseases, heavy rains, floods, drought and hailstones and can produce relatively safe food (fish and vegetables) with reduced environmental hazards (Azad, 2015). The present review on aquaponics in Bangladesh, is aiming to draw attention of the health-concious people of this country to expand the use of this technology for sustainable and healthy food production as well as to drag heed of researchers to explore innovations in aquaponic system through research.

\section{Materials and Methods}

The study was conducted based on the information through review of related thesis, journals, reports, and books. Some practical knowledge was gained through working experience in aquaponics laboratory, attending different seminars on aquaponics and observing research presentation related with aquaculture, agriculture and aquaponics. The necessary data were collected from internet, different annual statistical yearbooks of Bangladesh, National Fish week compendiums, newspapers, visiting aquaponics laboratories with different on-going researches and consulting associated consultants and researchers.

\section{Results and Discussion}

\section{Aquaponics}

The word "aquaponics" is derived from two words 'aquaculture' (raising aquatic animals such as snails, fish, crayfish, or prawns in tanks) and 'hydroponics' (growing plants in soil-less media) (Salam et al., 2014). Aquapoincs is a sustainable food production system that combines traditional aquaculture with hydroponics in a symbiotic environment. The key to aquaponic system is that the waste products of the biological system serve as nutrients to the other system and the water is re-used through biological filtration (Bethe, 2014). Simply, aquaponics is the integration of recirculating aquaculture and hydroponics (Rakocy and Brunson, 1989). And recirculating aquaculture is that aquaculture method where the same water is reused again and again through biological filtration and recirculation. In other words, aquaponics is a unique method of growing life. It combines gardening and a fish tank together in an independent, self-sufficient, and symbiotic system that mimics natural interactions of ecosystems and produces both plant and animal life. There are an infinite number of different designs and setups for an aquaponic system, but a few things remain constant: water is cycled and used as both a habitat for the fish and nutrients for the plants, and the plants are not grown in a traditional soil medium, but sit in and are supported mostly or even entirely by water. In aquaponics, the integration of fish and plants results in a polyculture that increases diversity and yields of multiple products (Salam, 2012). In fact, recent advances by researchers and growers alike have turned aquaponics into a working model of sustainable food production (Roy, 2012).

\section{Principles of aquaponics}

Aquaponics uses the water tank to circulate through a grow bed where the plants are grown. Nitrifying bacteria convert fish wastes into plant- available nutrients. The plants use the nutrients as their main nutrient supply. The fish benefit from the process also, as the water is filtered by the plants, giving the fish clean water to live in. With aquaponics, both the fish and plants not only grow well, but also flourish.

\section{Mechanism of aquaponic cycle}

In an aquaponic system, fish consume food and produce waste (mainly ammonia). Ammonia is hazardous to fish, even in small quantities $(0.04 \mathrm{mg} / \mathrm{l})$ and toxicity increases in relation to $\mathrm{p}^{\mathrm{H}}$ and temperature. Bacteria consume fish waste, decaying plant matter and uneaten food. The beneficial bacteria (Nitrosomonas) convert ammonia $\left(\mathrm{NH}_{3}\right.$ or $\left.\mathrm{NH}_{4}{ }^{+}\right)$into nitrite $\left(\mathrm{NO}_{2}^{-}\right)$which is also toxic to fish. 
Then another type of beneficial bacteria (Nitrobacter) converts the nitrite into nitrate $\left(\mathrm{NO}_{3}{ }^{-}\right)$. The nitrate is primary source of plant nutrition and thereby these are removed from the tank water in which the fish live (Figure 01).

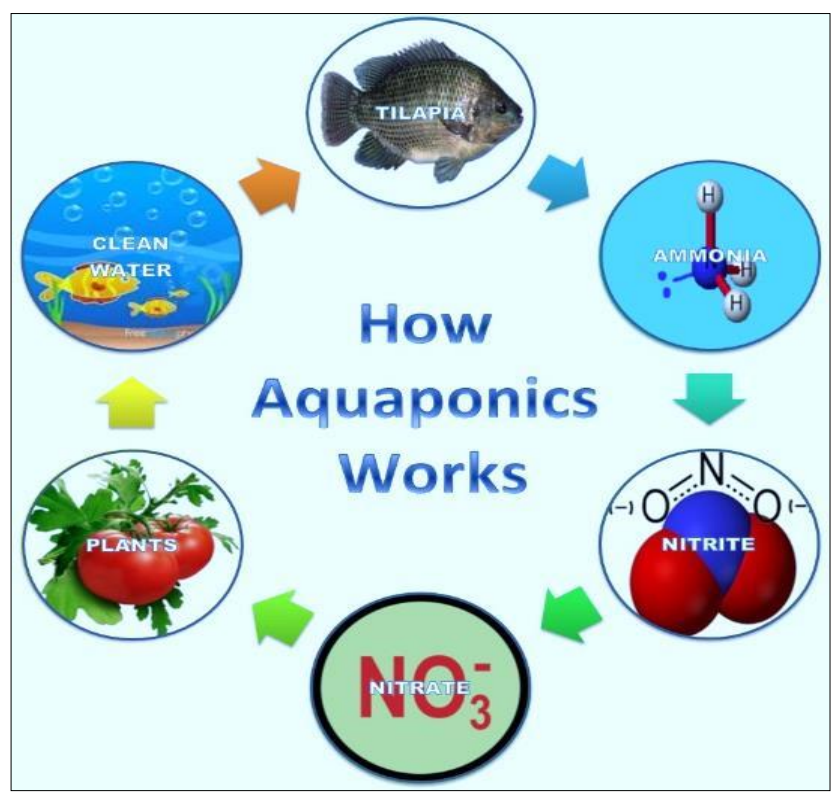

(a)

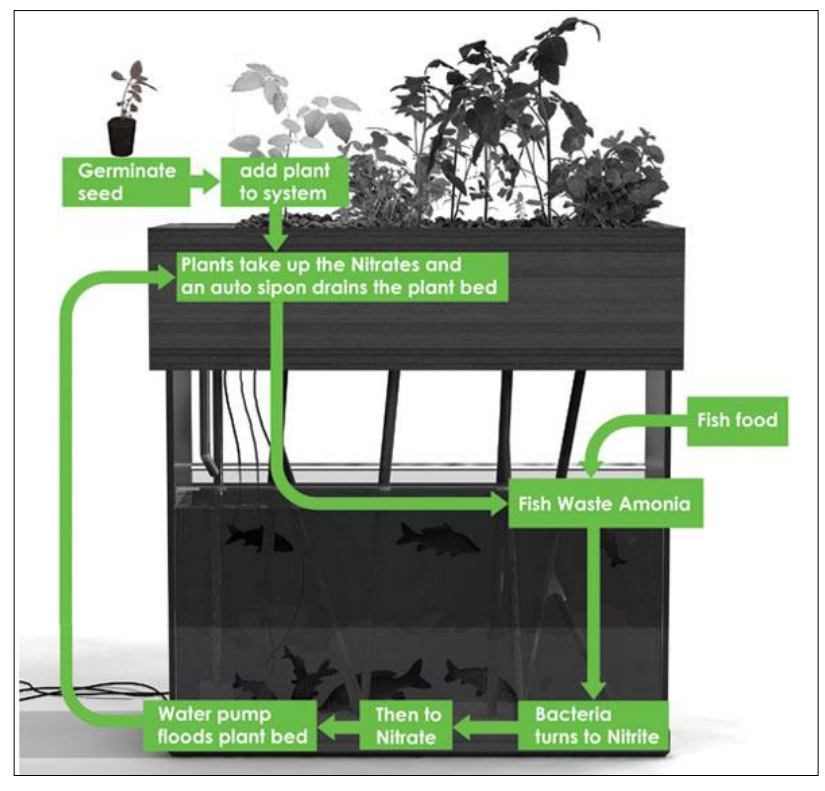

(b)

Figure 01. Mechanism of aquaponic cycle (a. Dimitrijevic, 2013; b. Larry, 2013).

When the system is in balance, the water becomes crystal clear and ammonia and nitrite level become nearly zero (Roy, 2012). In aquaponics, nitrate in excess is used for valuable plant production instead of being removed in gaseous form in denitrification units (Van Rijn, 2013). In other words, in this system, constant flow of water is maintained which gives steady supply of nutrients to the plants (Rakocy et al., 2004). Therefore, in this process, a synergistic relationship is created between fish, plants, bacteria, and other organisms in the system that recycles nutrients and eliminates polluted discharges (Nelson and Pade, 2008). Aquaponics combines the advantages of both hydroponics and aquaculture, while eliminating the disadvantages of both systems. It also reduces operating costs in comparison to either of these methods alone (Salam et al., 2013).

\section{Main components of an aquaponic system}

- Fish tank

- Grow bed

- Aeration pump

- Biofiltration

- Mechanical filtration

- Medium for media based system

- Fish and plants (seed)

- Water

\section{Main factors for a successful system}

- Optimum Dissolved Oxygen ( $>3 \mathrm{ppm})$

- Suitable water temperature $\left(28-32^{\circ} \mathrm{C}\right)$

- Optimal range of pH (6 - 9) (Boyd, 1982; Villaverde, 1997; Beveridge and McAndrew, 2012)

- Water hardness in suitable ranges 
- Required amount of nutrients (micro and macro-nutrients for plants) (Ragnarsdottir et al., 2011; Sonneveld and Voogt, 2009; Sverdrup et al., 2011)

- Regular water testing and keeping records

\section{Types of aquaponic system}

There are three types of aquaponic system practiced in the world including Bangladesh (Azad, 2015). They are-

a) Media based aquaponic system

b) Nutrient Film Technique (NFT) and

c) Floating raft technique and

\section{a) Media based aquaponic system}

The media based aquaponics is the most common system used all over the world, especially Bangladesh. In this aquaponic system, plants are grown in the media where water from the fish tank is supplied. Plants absorb the water and take nutrients as it flows through plant roots (Rakocy, 1999). Then the clean water returns to the fish tank (Figure 02). Some water is lost through transpiration, evaporation, grow bed media and by the leaf surface.

There are various media that are used for plant production in aquaponic system. Each media has advantages and disadvantages. A good medium for plant growth creates a nutrient pool around the plant root zones and provides adequate air space for respiration (Sikawa and Yakupitivage, 2010).

This system requires less management practice and the fewest components. It is the appropriate type for the beginners. This becomes relatively more important than other types of aquaponic systems because the presence of a media can possibly eliminate the need for a separate settling tank and biofilter (Rakocy et al., 2006).

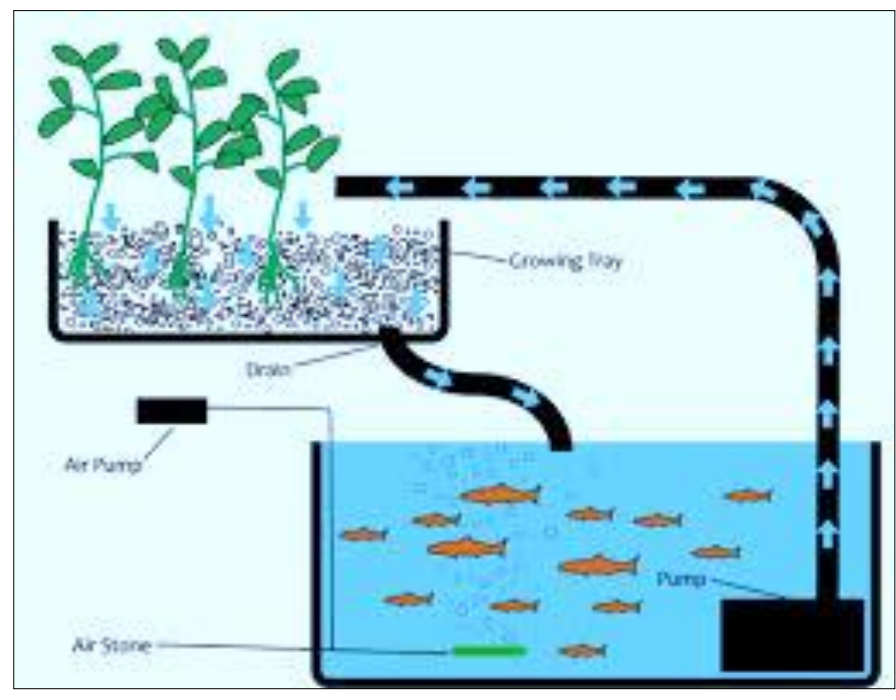

Figure 02. Media based aquaponic system (Mediawiki, 2014).

\section{b) Nutrient Film Technique (NFT)}

NFT (Nutrient Film Technique) is a method in which the plants are grown in long narrow channels or pipes. Small holes are made into pipe where plastic glass/ cups are placed. Plants are grown in glasses allowing their roots to access the water and absorb the nutrients. A thin film of water continuously flows to the channel which provides water, nutrients and oxygen to the plant roots (Figure 3). Plant roots are being exposed to nutrient rich running water that provides continuous supply of nutrients to the plants (Wilson, 2005). In this technique, the bio-filter becomes crucial as there is no large surface area whereby bacteria communities can develop (Nelson and Pade, 2008). Generally NFT is suitable for green leafy vegetables. 


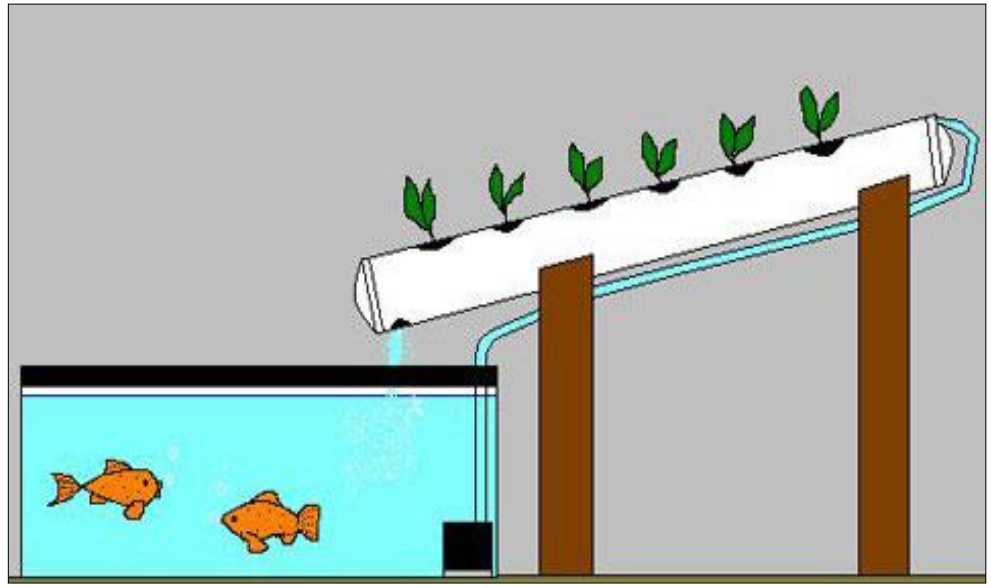

Figure 03. Nutrient Film Technique (NFT) (Sibinga, 2016).

\section{c) Floating raft technique}

In this system the plants are grown on Polystyrene boards (rafts) that float on top of water. Holes are made into boards and net pots are fitted. Plants are either grown directly into the bed, or transplanted from other growing area. The plant roots are always immersed into the water under the boards (Figure 04). The disadvantage of this system is that the roots remain exposed in the water which can be damaged by clogging by pollutants and by other aquatic organisms (Rakocy et al., 2006).

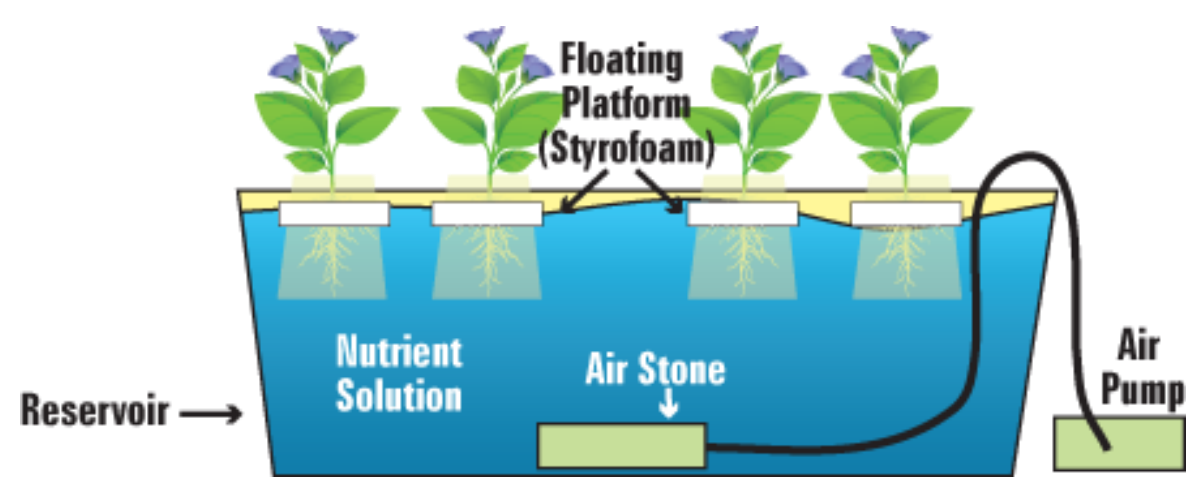

Figure 04. Floating raft technique (Newsletter, 2013).

\section{Plants adapted to aquaponics}

The selection of plant species adapted to hydroponic culture in aquaponic system is related to stocking density of fish tanks and subsequent nutrient concentration of aquacultural effluent. In aquaponics, various types of leafy vegetables and plants can be grown such as okra (Salam et al., 2013; Azad, 2015), raddish, lettuce (Mader, 2012), water spinach (Bethe, 2014), indian spinach, tomato (Salam et al., 2014), capsicum, cucumber, cabbage, carrots, mints etc. Lettuce, herbs and specially greens (spinach, chives, basil and watercress) have low to medium nutritional requirements and are well adapted to aquaponic systems. Plants yielding fruit like tomatoes, peppers, strawberries (Roosta and Afsharipoor, 2012) and cucumbers have a higher nutritional demand and perform better in a heavily stocked, well established aquaponic system.

\section{Suitable fish species for aquaponics}

Several warm water and cold water fish species are adapted to recirculating aquaculture systems, including tilapia, trout, perch and bass (Diver, 2006). In most aquaponic systems, fishes are cultured in tank, but all types of fish are not suitable. Fishes those are hardy and can tolerate wide range of water quality parameters are only suitable in tank culture. Therefore, most commercial aquaponic systems in Bangladesh are based on tilapia (Salam et al., 2014; Azad, 2015; Bethe 2014). Because tilapia 
(Oreochromis mossambicus) can tolerate poor water quality such as wide range of salinity, temperature, low dissolved oxygen levels and high ammonia concentrations (Bishop et al., 2009; Johanson, 2009; Boyd, 1990). It is very tasty, highly nutritious, popular and well accepted fish all over the world (FAO, 2007). The water quality parameters have less effect on tilapia than other fish species grown in commercial farming (Popma, 1999).

\section{Current status, limitations and remedies}

Bangladesh is an over- populated country blessed with huge water resources, but with limited land resources. The country has achieved $4^{\text {th }}$ position among the world's major aquaculture practicing countries in terms of fish and shrimp production (FAO, 2014). Now-a-days, aquaculture is going towards intensification in Bangladesh due to tremendous population growth. On the other hand, Bangladesh is also an agro-based country where about $75 \%$ people are directly or indirectly involved in agriculture. But land area for agriculture is also decreasing day by day for the same reason. At this situation, it was a crying need to find out an innovative technology for more food (fish and vegetables) production from per unit of area. That's why, in Bangladesh a sustainable technology for food production- aquaponics was started at Bangladesh Agricultural University (BAU), Mymensingh through research. Subsequently it was disseminated in other public universities and different research institutes. In these institutions, different research are being conducted on the aquaponics to examine suitable media, favorable culture system, adaptable plants and fish species for aquaponics. And the new findings from research are being distributed all over Bangladesh.

In the country, media based system is the most common style of aquaponic design used in backyard, rooftop or balcony of the houses. Deep flow/raft design is hardly used in commercial situations and NFT is the least used design in both backyards and commercial systems. In media based system, different inorganic media like gravels, bricklets, saw-dust (Salam et al., 2014) etc. or different organic media like coconut fiber, husk and dust, discarded tea leaves, water hyacinth roots etc., even the mixture of inorganic and organic media in different layers (Azad, 2015) are being used as growing media for plants in Bangladesh.

Moreover, an innovation of aquaponics technology - vertiponics (aquaponics which is done vertically) is also being used for research purpose. This can be done to reduce pressure on land and also to produce more food from small land area. For this, some PVC pipes of $4.5 \mathrm{ft}$ with 25-30 holes in each are set up vertically and coconut fiber or other media are filled in the holes where the plants are grown. In small area (1 sq. ft.), a great variety of crops like tomato, strawberry, lettuce, mint etc. can be produced in this system. So, it is very well fitted in small country like Bangladesh.

In urban, semi-urban and rural area of Bangladesh, aquaponics is being practiced for synchronized production of more fish and vegetables and through this technology, people are efficiently utilizing their unutilized area/land of the houses.

However, there is a deficiency of available research to encourage the development of economically efficient aquaponic systems in Bangladesh. Although many studies have addressed some scientific aspects, there has been limited focus on commercial impersonation. Moreover, aquaponics as an effective and sustainable technology has not become much popular all over Bangladesh till to date.

Hence, more research on aquaponics, especially for use in commercial aspects, need to be conducted with utmost priority and general people of rural and urban area should be informed thoroughly about this technology and made interested to use it practically. It is hoped that if the technology can be applied extensively in Bangladesh for sustainable food (fish and vegetables) production, there will be no food insecurity and food unsafety in future in the country.

\section{Future prospects}

Aquaponics is an up-to-date food production technology. In this system, higher amount of fish and vegetables can be cultured in small area at the backyard, balcony or rooftop of the house/building. Consequently, not only food transportation cost can be reduced (Salam et al., 2013), but also quality food can be obtained. Bangladesh, being small, has limited area for fish and vegetable production. So their productions are also low. But people's demands for food are increasing due to huge population growth. For instance, the present per capita annual fish consumption in Bangladesh stands at about 
$19.30 \mathrm{~kg} /$ year against a recommended minimum requirement of $21.90 \mathrm{~kg} /$ year; hence there is still need to improve fish production for more consumption in the country (DOF, 2013). On the other hand, the availability of vegetables per day for a person in this country is only 82 grams, whereas the nutritionists suggest that on an average, a person should take at least 235 grams of vegetables a day to maintain good health. This standard is also based on the assumption that other nutritious food items like meat, milk, egg, fruits etc. are also consumed. But these foods are also in scarce supply in Bangladesh. Hence, the standard requirement of vegetables for Bangladeshi people might be much higher than 235 grams per day. If in Bangladesh, vegetable requirement is calculated based on a conservative estimate of 235 gm per day, the present annual vegetable requirement would stand at 13.72 million $\mathrm{mt}$ for the current population of 160 million. In order to raise total vegetable production to 13.72 million $\mathrm{mt}$, we need to increase production by 8.94 million mt (Roy, 2012). In this situation, we need such an environmental friendly and sustainable technology for food production which can handle current problems efficiently. Aquaponics is that type of technology which can produce more fish and vegetables simultaneously per unit of area (Jahan, 2014). Not only that, but also the analysis of previous scientific papers shows that in aquaponic system the water use is efficient, fish and vegetable production is higher than the conventional aquaculture and agricultural system (Azad, 2015). In terms of aquaculture, higher level of consumption may create scarcity of water. For example, for extensive aquaculture $45 \mathrm{~m}^{3}$ and intensively mixed culture, $2.7 \mathrm{~m}^{3}$ water are needed. On the contrary, in the aquaponic system, water is re-circulated and thereby about $95 \%$ water can be saved (Dalsgaard, 2013). Further, compared to conventional agriculture, aquaponics uses less than $10 \%$ of water, depending on the climatic conditions (Bernstein, 2011). Moreover, Aquaculture operation solely depends on ground water which is depleting the ground water level day by day (Azad, 2015). Agricultural lands are also being converted to multiple uses day by day that is creating pressure on natural resources. But only aquaponics can solve these problems (Azad, 2015). With the expansion of aquaculture, there has been increasing trend to use more chemicals in every aspect. The higher use of chemicals causes the water pollution. In addition, the excess feed used in aquaculture may also cause pollution (Bethe, 2014). Further, to keep pace with the growing food demand, farmers are using various chemicals to boost up cereal production that creates human health hazards as well as other environmental problems around the world. Hence, food safety has become a question throughout the world including Bangladesh. But aquaponics is eco-friendly and stable food production system (Salam et al., 2013) which can produce relatively safe food (fish and vegetables) with reduced environmental hazards. Because in this system, no additional fertilizer/chemicals are used for vegetable production as fish wastes act as nutrients for plants. Besides, fish wastes are not needed to dispose. The fish used in the system can be fed with low-cost home-made feed, Metaphera posthuma, larvae of insects and even duck-weed. A harmful by-product of fish becomes a beneficial input for plant production in aquaponic system (Rakocy and Hargreaves, 1993). There is no need to plough the soil between two crops in this system. As here, plants are cultivated in soil-less media, there is no possibility of soilborne diseases. The self contained system prevents weeds and other pests from inhibiting plant growth. In this system, the growth of fish and plants are significantly faster. Through this system, organic production of fish and plants can be obtained all the year round. This is one type of integrated system which causes reduced running costs relative to either system in isolation. Moreover, integrated nutrient management improves the physical, chemical and biological properties of soil less vegetable culture as well as increase the productivity. In this system, food can be produced very easily in drought or places with poor soil quality (Salam et al., 2013), which is very important at the adverse geographical aspects of Bangladesh. If the rural household, landless, urban and slum dwellers use this technique to produce fish and vegetables, it will reduce the malnutrition problem of our country and enhance food security (Azad, 2015). At present, there is scarcity of chemical-free organic products in the market. The aquaponic system can solve the problem and reduce the costs for chemical fertilizer (Jahan, 2014). This ultimately suggests that chemical-free, fresh, nutritious vegetables and good quality fish can be produced through aquaponic system and thereby sound health can be maintained (Azad, 2015). Therefore, this technology might be the key future driving force in terms of building healthy and sustainable food producing Bangladesh.

\section{Conclusion}

Aquaponics, as an innovative technology, has been appeared in Bangladesh. Not only, enough vegetables per unit of area can be produced through this technology, but also growth of fish is 
satisfactory. But its acquaintance and popularity has not been spread all over the country yet as much as it is required in small country like Bangladesh. Moreover, more research needs to be conducted to extend its use in commercial aspects. This technology can be applied in both of rural and urban area, even in arid regions to produce available chemical-free and organic products, which can ensure food safety and food security all over the country. Suitability of this system can also provide better opportunities to fulfill the nutrition demand and to maximize use of land and water. Governments, businesses and individuals alike should therefore support and encourage the use of aquaponics at all levels.

\section{References}

[1]. Ahmed, N. \& Garnett, S. T. (2011). Integrated rice-fish farming in Bangladesh: meeting the challenges of food security. Food Security, 3(1), 81-92.

http://dx.doi.org/10.1007/s12571-011-0113-8

[2]. Azad, K. N. (2015). Comparative study of okra production using different bedding media in aquaponic system. MS Thesis, Department of Aquaculture, Bangladesh Agricultural University, Mymensingh.

[3]. Bernstein, S. (2011). Aquaponic gardening: a step-by-step guide to raising vegetables and fish together. New Society Publishers: Gabriola Island, BC, Canada, 256.

[4]. Bethe, L. A. (2014). Effect of foliar spray of compost tea on water spinach (Ipomoea aquatica) in Aquaponic System, MS Thesis, Department of Aquaculture, Bangladesh Agricultural University, Mymensingh.

[5]. Beveridge, M. C. \& McAndrew, B. (Eds.). (2012). Tilapias: biology and exploitation (Vol. 25). Springer Science \& Business Media.

[6]. Bishop, M., Bourke, S., Connolly, K. \& Trebic, T. (2009). Baird's village aquaponics project final report. McGill University, Bellairs Research Institute, Holetown, St. James, Barbados.

[7]. Boyd, C. E. (1982). Water quality management for pond fish culture. Elsevier Scientific Publishing Company.

[8]. Boyd, C. E. (1990). Water quality in ponds for Aquaculture. Alabama Agricultural Experiment Station, Auburn University, Auburn, Alabama, USA. p. 482.

[9]. Dalsgaard, J., Lund, I., Thorarinsdottir, R., Drengstig, A., Arvonen, K. \& Pedersen, P.B. (2013). Farming different species in RAS in Nordic countries: Current status and future perspectives. Aquaculture Engineering, 53, 2-13. http://dx.doi.org/10.1016/j.aquaeng.2012.11.008

[10]. Dimitrijevic, I. (2013). Aquaponics: A Mechanism that Combines Plants, Fish and Water. Blog, Home \& Lifestyle, March 21, 3013. Available at www.ivandimitrijevic.com.

[11]. Diver, S. (2006). Aquaponics-Integration of hydroponics with aquaculture. ATTRA-National Sustainable Agriculture Information Service. Available at http//attm.ncat.org/attm pub/PDF/aquaponics.pdf.

[12]. DOF (2013). Fisheries Statistical Yearbook of Bangladesh. Fisheries Resources Survey System (FRSS), Department of Fisheries, Bangladesh, 29, 1- 44.

[13]. FAO (2007). National Aquaculture Sector Review. Libyan Arab Jamahiriya, Rome, Italy.

[14]. FAO (2012). The state of world fisheries and aquaculture. Food and Agriculture Organization of The United Nations, Rome, 2012.

[15]. FAO (2014). The state of world fisheries and aquaculture. Food and Agriculture Organization of The United Nations, Rome, 2014.

[16]. Jahan, N. (2014). Tomato (Solanum Lycopersicum) production in aquaponic sysyem in different media. MS Thesis, Department of Aquaculture, Bangladesh Agricultural University, Mymensingh.

[17]. Johanson, E. K. (2009). Aquaponics and hydroponics on budget. Journal Technical Directions, 69 (2), 21-23.

[18]. Larry, D. (2013). How fish waste is used in an aquaponic system, June 24, 2013. In: Aquaponics ideas online: An easy way to grow fish and organic vegetables together. Available at Available at http://aquaponicsideasonline.com/how-fish-waste-is-used-in-an-aquaponic-system.

[19]. Mader, J. (2012). Plant growth in aquaponics system through comparison of different plant media, Senior Honors Project, Lynchburg College, Virginia, USA. p. 23.

[20]. Mediawiki (2014). Aquaponics system prototype, published on 2 November, 2014. Available at http://www.thegrowing.org/wiki/index.php/Aquaponics_System_Prototype. 
[21]. Nelson, R. \& Pade, J. S. (2008). Aquaponic food production. Nelson and Pade, Inc., Montello, WI. p. 218.

[22]. Newsletter (2013). Why hydroponics. Hummert International E-news, October, 2013, Newsletter, vol.-22. Available at www.hummert.com.

[23]. Popma, T. (1999). Tilapia: life history and biology. Southern Regional Aquaculture Center Publication, 283.

[24]. Ragnarsdottir, K. V., Sverdrup, H. U. \& Koca, D. (2011). Challenging the planetary boundaries. In: Basic principles of an integrated model for phosphorous supply dynamics and global population size. Applied Geochemistry, 26, S303-S306. http://dx.doi.org/10.1016/j.apgeochem.2011.03.088

[25]. Rakocy, J. E. \& Brunson, M. W. (1989). Tank culture of tilapia. College Station, Texas: Southern Regional Aquaculture Center, 5-10.

[26]. Rakocy, J. (1999). Aquaculture engineering - The status of aquaponics, Part 1. Aquaculture Magazine, 25(4), 83-88.

[27]. Rakocy, J. E. \& Hargreaves, J. A. (1993). Integration of vegetable hydroponics with fish culture: a review. American Society of Agriculture Engineers, St. Joseph, MI (USA), 112-136.

[28]. Rakocy, J. E., Bailey, D. S., Shultz, C. \& Thoman, E. S. (2004). Update on tilapia and vegetable production in the UVI aquaponic system. Proceedings from the $6^{\text {th }}$ International Symposium on Tilapia in Aquaculture, 2, 676-690.

[29]. Rakocy, J. E., Masser, M. P. \& Losordo, T. M. (2006). Recirculating aquaculture tank production systems: aquaponics- integrating fish and plant culture. SRAC Publication, 454 1-16.

[30]. Roe, B. \& Midmore, D. J. (2008). Sustainable aquaponics. Center for Plant and Water Science. CQUniversity, Rockhampton, Queensland, Australia (Issue 103. Hydroponics and Greenhouses).

[31]. Roosta, H. R. \& Afsharipoor, S. (2012). Effects of different cultivation media on vegetative growth, ecophysiological traits and nutrients concentration in strawberry under hydroponic and aquaponic cultivation systems. Advances in Environmental Biology, 6(2), 543-555.

[32]. Roy, M. (2012). Feasibility Study of Aquaponics in Polyculture Pond, MS Thesis, Department of Aquaculture, Bangladesh Agricultural University, Mymensingh.

[33]. Salam, M. A. (2012). Raft aquaponics for sustainable fish and vegetable production from high density fish pond. $5^{\text {th }}$ Bi-annual Fisheries Conference and Research Fair 2012, Bangladesh Fisheries Research Forum, 18-19 January, 2012 at BARC, Dhaka.

[34]. Salam, M. A., Asadujjaman, M. \& Rahman, M. S. (2013). Aquaponics for improving high density fish pond water quality through raft and rack vegetable production. World Journal of Fish and Marine Sciences, 5(3), 251-256.

[35]. Salam, M. A., Jahan, N., Hashem, S., \& Rana, K. M. S. (2014). Feasibility of tomato production in aquaponic system using different substrates. Progressive Agriculture, 25, 54-62.

http://dx.doi.org/10.3329/pa.v25i0.24075

[36]. Sibinga, N (2016). Aquaponics: An Innovative Opportunity. In: Environmental stewardship, Sustainable land management, preservation of our rural character. Gallow Runs Watershed

[37]. Sikawa, D. C. \& Yakupitiyage, A. (2010). The hydroponic production of lettuce (Lactuca sativa L.) by using hybrid catfish (Clarias macrocephalus $\times$ C. gariepinus) pond water: Potentials and constraints. Agricultural Water Management, 97(9), 1317-1325.

http://dx.doi.org/10.1016/j.agwat.2010.03.013

[38]. Sonneveld, C. \& Voogt, W. (2009). Plant Nutrition in Future Greenhouse Production. In Plant Nutrition of Greenhouse Crops. Springer, Netherlands, 393-403.

http://dx.doi.org/10.1007/978-90-481-2532-6_17

[39]. Sverdrup, H.U. \& Ragnarsdottir, K.V. (2011). Challenging the planetary boundaries II: Assessing the sustainable global population and phosphate supply, using a systems dynamics assessment model. Applied Geochemistry, 26, S307-S310.

http://dx.doi.org/10.1016/j.apgeochem.2011.03.089

[40]. Van Rijn, J. (2013). Waste treatment in recirculating aquaculture systems. Aquaculture Engineering, 53, 49-56. http://dx.doi.org/10.1016/j.aquaeng.2012.11.010

[41]. Villaverde, S. (1997). Influence of $\mathrm{pH}$ over nitrifying biofilm activity in submerged biofilters. Water Reearch, 31(5), 1180-1186. http://dx.doi.org/10.1016/S0043-1354(96)00376-4

[42]. Wilson, G. (2005). Aquaculture proves superior to inorganic hydroponics. Aquaponics Journal, $39,14-17$. 